\title{
THE ECONOMICS OF AIR POLLUTION: CENTRAL PROBLEMS
}

\author{
Harold WoloziN*
}

\section{INTRODUCTION}

Afflicting damage and distress upon human, animal, and plant life, polluted air blankets most populated areas of the globe. The salient economic consequence of this is that pure or relatively unpolluted air is no longer a free good; it costs money to go where air is relatively cleaner, it costs money to trap pollutants before they escape into the air. Yet, by and large, those who are responsible for pollution do not bear the cost of the pollution they create; it is an "external" cost of production and consumption.

Born of this condition, the economics of air pollution is largely directed to two broad areas, both difficult assignments: ( $\mathrm{I}$ ) measuring the costs to individuals and society at large of the diffusive despoiling of the atmosphere (and the corresponding benefits of cleaning it up) and (2) determining economic measures to stimulate and/or coerce polluters to eliminate or at least cut down their emissions of destructive gases and particulate matter.

Air pollution-smoke and other airborne particles-has accompanied the growth of industrialization since its early days. However, in the last two decades overwhelming evidence has begun to accumulate that polluted air is a serious threat to the quality of life, even to man's continued existence itself; projections of economic growth and population expansion to the year 2000 pose the threat of a vast increase in the already high level of air pollution unless effective measures are taken to control it. It is in recognition of both the present and potential costs to society that increased importance has been given to the devising of means to detect, control and abate air pollution. It is also becoming clear that because of the damage to life and property, expenditures on air pollution control and abatement are as essential to society, if not to individual polluters, as investment in education, urban renewal, and other investment in social capital. In a basic sense, is not investment in air pollution control also investment in human resources ? ${ }^{1}$

The primary purpose of this paper is to survey and evaluate the state of the art in the two broad areas of interest outlined above. I hope, in describing the nature of the difficulties and dilemmas that confront public and private efforts to devise

- A.B. I942, Tufts University; Ph.D. 1955, Columbia University. Professor of Economics and Chairman, Department of Economics, University of Massachusetts at Boston. Editor, The Economcs of ArR Polzution (1966).

${ }^{2}$ A decade ago Kenneth Galbraith's book, The Affuent Society (1958), argued tellingly for a broadening of the conventional definition of social capital to include investment in human resources. Thus far, it is principally in educational expenditure that this view has prevailed. 
means and alternative techniques for coping with air pollution, to explore to what extent these very difficulties, when objectively evaluated, may bear within themselves the seeds of workable and practicable solutions to the problem. In this respect, we must recognize and include in our calculations the fact that air pollution is but one of several severe sources of an accelerated deterioration in the quality of the environment in which man works and lives. As we will see, the need for simultaneous solutions could result in certain savings, i.e., "external economies," such as the lowering in air pollution which might result from expenditures on public mass transportation utilizing electricity.

\section{I}

\section{Measuring Air Pollution Costs and Benefits}

The singular characteristic of the extensive air pollution accompanying the rising levels of production and consumption in our society is its pervasiveness, a quality that makes especially difficult both its control and the measurement of its cost. Unlike water pollution, air pollution can be both a singularly local blight and a particularly wide-ranging one, limited only by the course of prevailing winds. It attacks man directly as well as his environment. Its damage to humans, animals, and crops can be both acute and chronic. The magnitude and implications of the latter are only beginning to be realized and are causing considerable concern, especially to agricultural and health specialists.

Air pollution cuts down visibility on airport runways and on our turnpikes. It dirties and decays buildings and works of art. A slow rise in the temperature of the earth has been attributed to air pollution; and it is suspected of altering genes of people, so that there may be a change in the inherited characteristics they pass on to their descendants as well as possible mutations. ${ }^{2}$ The sources of air pollution are diverse and multitudinous, many resulting, paradoxically, from activities designed to alleviate other forms of pollution. Once released into the atmosphere, primary and secondary pollutants, unlike those in water or sewage, are untreatable, often unpredictable in their effects, and difficult to detect and measure.

It is, therefore, not surprising that to come to grips with the economic impact of air pollution is not a simple matter and poses a fundamental question: Can we presume with any confidence to measure the total economic costs of air pollution? What does the pervasiveness of air pollution imply in respect to our ability to measure its effects and for the scale of resources which would have to be allocated to obtain reliable national estimates of air pollution damage? The problem seems to be twofold: Economists who have specifically been concerned with the total measurement problems have cast serious doubts on the value and reliability of existing national

\footnotetext{
'Remarks of Dr. Haagen-Smit before the American Meteorological Society, reported in the Washington Post, Feb. I, 1968, at 2, col. 6.
} 
estimates of damage based on currently accepted definitions. ${ }^{3}$ In the process they have understandably displayed some ambivalence; on the one hand, concern over the gravity of the pollution damage problem and, on the other hand, pessimism over what appears to be the exorbitantly costly as well as technically formidable task of arriving at defensible estimates of total damage and abatement costs. In view of the pervasive nature of air pollution, as we have briefly described it, this is understandable. The author of one of the pioneering explorations along these lines, Ronald Ridker, for example, although recommending an intensification of efforts to gather more data "collected specifically for the purpose of air-pollution research," concludes on the basis of his investigations that "data collection is a very expensive process," and he is "not at all certain" about the "payoff."

This ambivalence is also reflected in a paper delivered last year by Allen V. Kneese, who holds that estimates of national pollution costs are of a rather limited utility as an aid to decision-making, although, on balance, "they do have a certain usefulness." It would, however, be hard to disagree with Kneese that those national estimates which are available are "indefensible," and "all guesses" worthy only of abandonment. ${ }^{6}$ Kneese is not too concerned with the absence of reliable estimates; he reasons that "making improved decisions based on economic data does not necessarily require that we know the total costs and gains at all." Fiscal planners at the national level might well question this position on the grounds that devising and implementing rational policies for control cost considerable sums of money and, hence, justify serious effort to obtain reliable estimates of the total cost of air pollution and its abatement. It is also possible that serious, adequately funded efforts to produce national totals can be more productive than either of the two authors cited above seems to believe. Both types of estimates are essential; the global sets the necessary priorities and framework for the partial estimates. This is implicit in Kneese's position, in the article cited above, that the relationship between incremental costs and damage on a national level can be useful as a guide to setting advisable levels of damage and control outlays. However, the truth of the matter is that to obtain these incremental costs (they are first derivatives), data on total costs and benefits must first be estimated.

One point which is of considerable importance is the nature of the total cost function defining the relationship between total costs of pollution and level of pollution. On the basis of what we already know, it is difficult to agree that the shapes of air pollution cost and abatement functions are linear, as implied by Kneese.

\footnotetext{
${ }^{3}$ Remarks of Linsky, in Proceedings: The Third National Conference on Air Pollution 539 (Public Health Service Pub. No. 1649, 1967) [hereinafter cited as Proceedings].

- Ridker, Strategies for Measuring the Cost of Air Pollution, in The Economics of Air Pollution 87, roo (H. Wolozin ed. 1966).

${ }^{5}$ Kneese, How Much is Air Pollution Costing $U_{s}$ in the United States?, in Procespress, supra note 3 , at 529 .

- See id. at 530.

TId. at 53 I.
} 
Even on a priori grounds one might suspect that assuming linearity oversimplifies the problem. Perhaps we can demonstrate what nonlinearity could imply, utilizing as an example the functional relationship between the level of pollution and the magnitude of the costs of abatement. There are significant policy implications of such a nonlinear relationship. Figure I plots a hypothetical relationship, in an advanced industrial society, between various levels of pollution (measured by some composite index) and the total cost of abatement required to obtain each level of pollution measured on the horizontal axis. Two assumptions underlie this illustrative model: technology is assumed and the actual level of pollution at any given time is one point on the pollution scale. In other words, this is a static model depicting the inverse relationship between abatement costs and the level of pollution. What is under question is what happens as we move in either direction along the scale. If we go (Figure I) from point "P" toward point " $A$," the recognition or minimum prob-

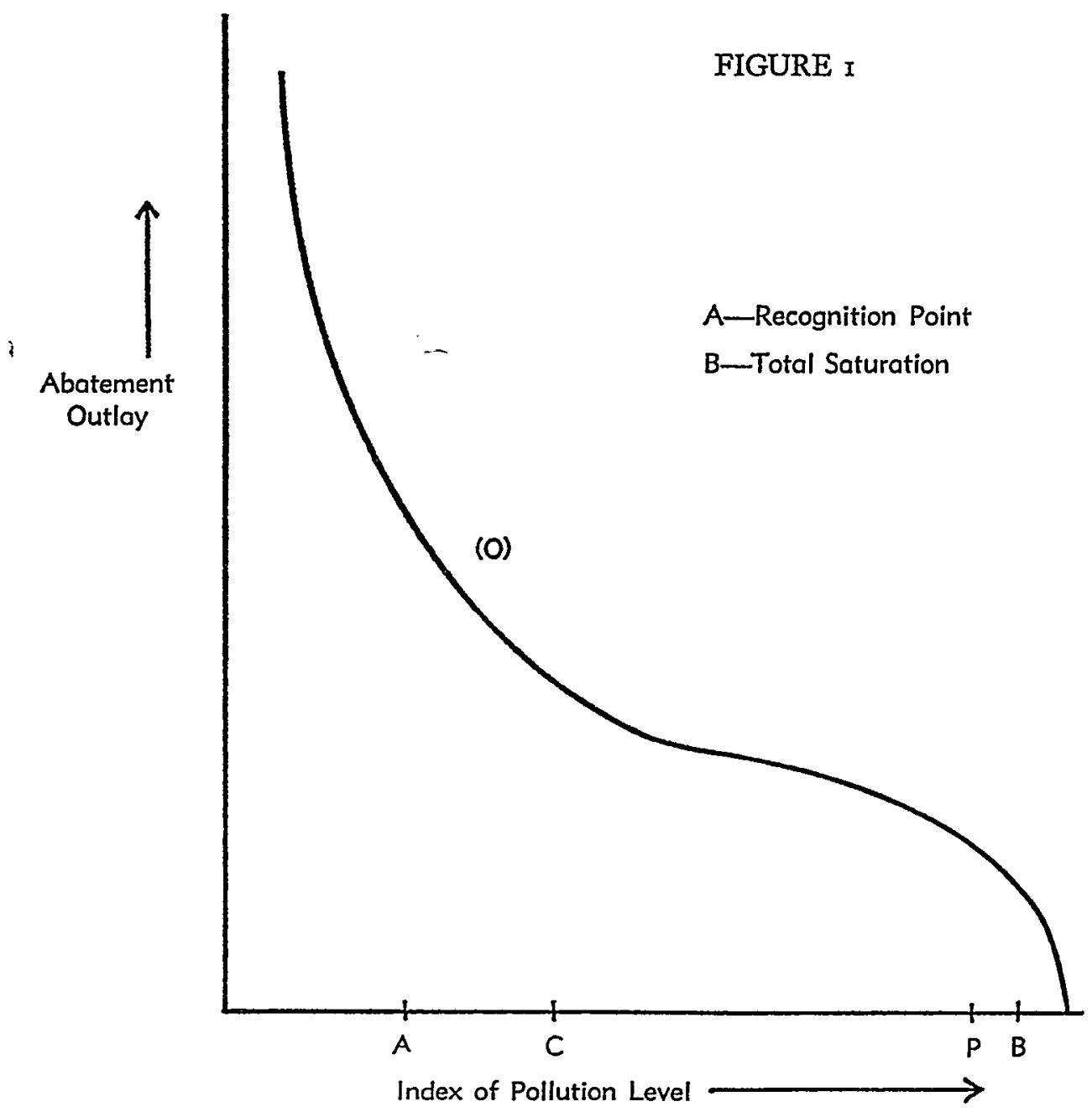


lem level-in other words, the point at which air pollution would be at a low level and just detectable-outlays for abatement would after a spell have to increase more rapidly as we reached successive and more difficult to obtain levels of cleaner air, and would soar as we approached "A." Contrariwise, if the alternative decision were to accept lower abatement outlays, then the choice would imply, correspondingly, an acceleration in damages. Such an abatement function, "O," would posit, initially, low returns to scale as abatement is initiated, near point " $B$," the saturation level on the pollution index. There would then be a rather long span over which returns to scale are increasing (between "P" and "C") and eventual entry into an area of diminishing returns to scale as the air is cleaned up. It is also possible that amounts of damage related to increases in pollution levels are nonlinear-an initial range of minimal damage, then a range of rapid rise in damage costs relative to pollution levels followed by a leveling off, even though this might not be reached except near the point of disaster. Such a damage function could be diagrammed as we have done for the abatement outlay function.

Even though the shapes of such functions could be quite different in real life than we have here posited, it should be clear that whatever their actual shape, knowledge of the fundamental relationships they depict could be of considerable importance, not to be dismissed as of marginal value. However, only systematic research can determine this. It should be pointed out that the cost function depicted in Figure I is based upon conventional assumptions in respect to returns to scale. If it were to turn out that the actual relationships were close to what we depict here, this would suggest some rather important conclusions. For example, on the basis of inspection alone it would follow that relatively modest increases in total abatement outlays would reduce the level of total damages more efficiently over one section of the range of pollution level than another part. This says somewhat more than the more conventional depiction of straight line incremental relationships assumed by Kneese in his representation of relevant benefits and cost concepts; $;$ although, consistent with the calculus of cost-benefit analysis, one would theoretically want to reach equality of incremental costs and benefits of abatement outlays.

Furthermore, it is possible that cost and abatement curves are kinked. It would follow that the derived marginal curves would be discontinuous, which could introduce considerable uncertainty in the determination of "appropriate" levels of support for resources and research to reduce damage control costs and otherwise to control air pollution. On balance, these possibilities would seem to justify attaching considerable importance to research on total outlay and cost functions.

However, this in no way detracts from the importance of estimating damages and control costs at the "problem shed" level and certainly does not dispute Kneese's contention that it is at this regional level that it would be easier-"more feasible and

\footnotetext{
${ }^{8}$ Id. at 53 I. I am indebted to my colleagues Leonard Kirsch and Louis Esposito for helping to clarify my thinking on these relationships.
} 
more relevant to decision-making"- to obtain "reasonably systematic analysis of damage and control costs.",

What should such estimates provide? On the damage side, the main categories of cost would include the effects of air pollution on life-human, animal, and planton materials, on maintenance and cleaning bills, and a wide range of indirect costs of smog. On the control cost side, pollution scientists would be concerned with the costs of abatement under existing technological possibilities as well as the savings in control costs which might be obtained from new technologies. This would include such things as new types of pollution-free transportation, new production techniques, new collection and treatment systems, and so on.

Given this qualitative difference in the problem, haye the relatively few studies of air pollution damage at the "problem shed" level been more successful than those on the national level? The answer seems to be "No." In spite of their more limited scope and relatively greater appeal to the specialist, those few studies of direct damages that have been done at the problem shed level have been consistently poor. Kneese, Ridker, and this author, among others, have amply documented this point, so that further elaboration here is unnecessary.

However, it would be helpful to enumerate some of the difficulties which confront the researcher. First of all, even though it is ostensibly more manageable, the concept of the air shed is inherently vague. We have already alluded to the problem of the pervasiveness of air pollution to which this is related. Secondly, many categories of damage resist precise measurement, and where experimental approaches are utilized results are often misleading. Thirdly, chronic as opposed to acute effects of air pollution are often undetected and, hence, uncounted. Yet in the long run their effects, particularly on human health and agricultural crops and animals, may dwarf the immediately measurable damages. ${ }^{10}$ Fourth, it is frequently difficult to isolate air pollution from other sources of damage. This problem is compounded when they interact and amplify each other. The questionable reliability of estimates of effects on property values is an easily demonstrated example of this. Yet, it is in this very area that some encouraging results have been obtained. ${ }^{11}$ Such limitations extend to a wide spectrum such as cleaning costs and health. Even though the seriousness of the latter is causing increasing concern to public health officials, the suspected heavy costs of ill health stemming from air pollution are virtually unknown. Fifth, indirect costs of control may even go undetected let alone measured. Finally, the use of data gathered for other purposes often turns out to be grossly

\footnotetext{
'Id. at 531 .

${ }^{10}$ As this author pointed out in an earlier article, the measurement of chronic cffects has been seriously neglected. Wolozin \& Landau, Crop Damage from Sulphur Dioxide, 48 J. FArM EcoN. 394 (1966). An excellent study of problem shed agricultural damage can be found in E. Landau, The Public Control of Air Pollution: A Case Study (mimeo. 1966) (unpublished dissertation).

${ }^{11}$ See Kneesc's reference to the work of Tom Crocker in Procendings, supra note 3, at 534.
} 
inadequate in isolating and measuring air pollution damage, especially where surrogates are relied upon.

Our ability to estimate the costs of alternative systems of pollution control at the problem shed level does not seem to be much better than it is in deriving national damage costs. Although there is a good deal of information on the costs of control utilizing specific processes and equipment, there are also basic disagreements such as in the case of automobile emission controls. And, as Kneese points out, when it comes to the questions of indirect effects and trade-offs between large-scale control measures involving location and alternative processes as opposed to conventional emissions controls, "information is nil."12

\section{II}

\section{The Problem of Control-Alternative and Complementary Policies}

The continuing debate among economists over air pollution control has centered on whether polluters of the air, be they businessmen engaged in activities which spew wastes into the air or consumers doing the same thing in driving automobiles or burning leaves, can be induced to take voluntary measures to eliminate or lessen their pollution in response to market incentives (or coercion), and how predictable the results would be; for under incentive systems there is the option not to be persuaded by the rewards. Specifically, market pressure would be exerted by imposing charges or effluent fees which would reflect the marginal costs of the pollution inflicted upon others. These effluent fees would be designed to bring the level of pollution down to tolerable and acceptable limits. The discussion in this paper will be confined to issues relating to the meaning and implications of the argument for resorting to primary reliance on the market mechanism to control air pollution.

Effluent fee schemes have been enthusiastically advanced as the logical alternative to direct governmental intervention through regulations stipulating standards and prohibiting certain pollution-creating activities. It should be pointed out that advocacy of effluent fee policy does not necessarily imply disagreement with parallel actions, such as subsidies of many sorts ranging from tax credits for air cleaning equipment and alternative processes to outright payment or reimbursement by government for control devices or relocation costs. (No such action as the latter has, to my knowledge, been seriously proposed.) Many proponents of effluent fees tend to minimize these other possibilities and suggest either implicitly or explicitly that effluent fees can do most of the job alone. The truth of the matter is, however, that with the emphasis placed by the Air Quality Act of $1967^{13}$ on government enforcement of air standards and the designating of air quality control regions, the trend seems to be toward increasing governmental assumption of direct responsibility

12 Id. at 534 .

128 r Stat. 485 . 
rather than any commitment to the indirect pressures operating through market incentives such as effluent fees. In a sense, the conceptun battle lines have been drawn.

A critical issue has been raised: to what extent can we reconcile the arguments for heavy reliance upon the market mechanism through the medium of emissi in or effluent charges with what appears to be the increasing evidence that air pollution is an externality which will require more than indirect coercion to control? To what extent should we consider seriously the advocacy of some experimentation with effluent fees. This has been advocated strongly by Crocker, Mills, and Vickrey. "Ideally," according to Crocker, "this charge would be levied upon the emitters at the level which would tend to equate the present value of receptor marginal damage costs to the present value of emitter marginal costs savings." Crocker would also reimburse those damaged, the "receptors." However, these economists differ in the extent to which they would place reliance upon such schemes.

In one sense, the enthusiasm for effluent fees has been directly related to the degree of antipathy for direct regulation, most noticeably in the case of Mills and least so with Vickrey. While direct regulation and subsidy certainly affect the shape of economic decisions and activity, this is a subject for separate treatment. However, they do have certain policy implications which are germane to the subject of this paper. Moreover, it is likely that many of the problems, particularly technological, confronting the implementation of voluntary techniques would not disappear with direct regulation.

Let us now look briefly at the main thrust of the arguments supporting effluent fee schemes. Mills, the most positive proponent of principal reliance on effluent fee schemes, bases his advocacy "on practical, rather than theoretical, grounds." $\mathrm{He}$ lists several reasons:: (I) "If each discharger is faced with the same schedule of effuent fees, abatem 2 rt is relatively cheap." "Complete flexibility" would be possible, if, in addition, it proved possible to confront dischargers with different effluent fee schedules according to the benefits to be derived from abatement. (2) Management rather than government officials are entrusted with the burden of investigation and decision-making. (3) "Dischargers" of effluents are provided continuous incentives to search for additional methods of abatement. (4) Any inability to measure the benefits and costs of abatement will show up "more quickly" with an effluent fee control program. Vickrey ${ }^{16}$ contributes the following pertinent points to the debate on effluent fee abatement schemes: (I) effluent fees are "at

\footnotetext{
14 T. Crocker, Some Economic Aspects of Air Pollution Control With Particular Reference to Polk County, Florida, U.S. Public Health Service Grant: AP-00389-02, Jan. 1968, at 282.

${ }^{25}$ Mills, Federal Fiscal Policy in Air Pollution Control, in Proceedings, supra note 3, at 574, 576-77. Mills discusses federal agencies' "dereliction of duty" in not adopting effluent fees. Id. at 577.

${ }^{10}$ Vickrey, Theoretical and Practical Possibilities and Limitations of a Market Mechanism Approach to Air Pollution Control, a paper presented at the annual meeting of the Air Pollution Control Association, Cleveland, Ohio, June II, I967.
} 
least in principle" highly flexible because they can be varied with changing circumstances including changing weather conditions, (2) management, and their technicians, are "in the best position" to devise the best solutions for abatement, and effluent fee schemes will best insure their cooperation, (3) "necessary discriminations" which accompany regulatory control will be minimized if these controls are adjuncts to effluent fee systems, (4) at the local level, the revenues resulting from effluent fees can serve as a substitute for other taxes which are "quite injurious in their effects," and (5) effluent fees force the administrator "to bring the problem into perspective" and may restrain the "pure air enthusiast" who might "be inclined to impose standards" entailing "too high a cost relative to benefits."17

Discussions of effluent fee schemes have reflected grave reservations as to their efficacy and practicability and such points as those covered in the preceding discussion have been the subject of considerable disputation. There are several questions which might be raised, particularly the following: (I) The first, reflecting a degree of skepticism on the efficacy of effluent fee schemes, is on the nature of their assumptions about business behavior. To support the contention that externalities can be internalized through effluent fees, proponents generally fall back upon a conventional economic analysis of the nature of business behavior in the modern world, a model of business behavior which has been questioned seriously in the literature on the subject and one which very few economists adhere to rigorously in explaining the behavior of the firm or industry. (2) Directly related to this is the tenuous nature of current theories and knowledge about the formulation of investment decisions in business firms (pollution abatement requires investment). (3) Formidable detection and monitoring problems are implicit in effuent fee schemes, a problem compounded by the primitive state of technology in these areas. (4) Finally, there is a genuine concern that effluent fees discriminate against small firms. Let us look briefly at each of these.

In the first point, what is at issue is the state of the art in the economic theory of the firm and the economics of industrial organization, which includes the structure of competitive relationships in industry. It is generally agreed, as this author has pointed out in another paper, ${ }^{18}$ that the neoclassical profit maximization model of business behavior ill fits the kind of business world in which effluent fee schemes would have to be imposed. One does not even have to replace the neoclassical model with a sociological analysis ${ }^{19}$ as certain economists and statisticians have suggested: There are other economic models such as Baumol's sales maximization model which describe a good bit of reality in the business world. How determinative would

\footnotetext{
${ }^{19}$ Id. at I, 2.

${ }^{18}$ Wolozin, Intransigent Economic Behavior in Air Pollution Control and Decision, a paper presented at the annual meeting of the Air Pollution Control Association, Cleveland, Ohio, June, Ig66.

${ }^{10}$ For a brief discussion of such sociological analysis, see remarks of Wolozin in Procendings, supra note 3, at 579-8I. See generally H. Wolozin, Toward an Interdisciplinary Model for Air Pollution Control (mimeo.) (Washington, D.C., I967).
} 
effluent fee schemes be? In other words, how predictable would be their results under such models? The record of directly applicable tax research is also not encouraging. ${ }^{20}$ One must not forget that no matter how coercive effluent fees might be in theory, compliance, requiring the installation of abatement equipment, alternative processes, or decisions to relocate, is voluntary. Furthermore, it should be noted that as unpredictable as compliance might be, the impact upon resource allocation is equally unpredictable.

The above leads to the second of our points: the complex and little known nature of the determinants of investment decisions in business firms. There is great dispute on the impact of investment credits, for example, as there is on the whole question of the effects on investment of the corporate income tax. Evidence to support the thesis that effluent fees will result in investment outlays on pollution abatement equipment is shaky. Uncertainty, the complex nature of capital markets, and other factors determining investment decisions would inject a good deal of indeterminateness into any attempt to predict responses to effluent fees. At a more personal level, this author has testimony from those close to the business world which casts further doubt on the efficacy of effluent fees. One former businessman writes me,

True, if you would base pollution control on a system of incentives, you might be disappointed. The marginal dollar gained for pollution control is hardly as exciting as the marginal dollar gained in expanding sales, creating new products or improving technology. This type of income promises growth and future profits. I think that many, if not most businesses have a shortage of key personnel and they would rather use this resource to develop the mainspring of their profits than to maximize their pollution subsidies. ${ }^{21}$

Vickrey has presented an eloquent description of the difficulties of monitoring and metering with the present grossly imperfect state of our technology.

The real problem which advocates of efluent charges must face is the problem of metering, or of estimating in some way the amount of effluent actually generated by various emitters. Here the problem of air pollution is seen to be a particularly difficult one in that the number of small emitters and of the emitters difficult to meter effectively is large and their contribution to the problem is too great to be ignored. ${ }^{22}$

Vickrey goes on at some length to catalogue difficulties of inspection, measurement, and the like. Given the immensity of the monitoring and metering problem, and we have not even spoken of personnel and recruiting problems, one might conclude that simplicity should be high on the list of criteria for air pollution policy. On this count, effuent fee schemes might well founder as opposed to more direct regulatory measures. For example, it might not be so impractical to require regular tuning

\footnotetext{
10 Remarks of Wolozin, in Proceedings, supra note 3 , at 580 .

21 Letter from Robert E. Kohn to Harold Wolozin, July 4, 1967.

sa Vickrey, supra note 16 , at 5 .
} 
of automobiles at the expense of the community. This would be tantamount to compensating the emitter for his expense but in a much simpler manner. The same reasoning, for example, might be applied to the providing of scrubbing and other devices to industrial polluters, in return for guaranteed lowering of emission levels.

Finally, let us consider, briefly, the possibility that effluent fees discriminate against small firms. The reasoning here is simple, and it hinges on the cost of abatement equipment. The smaller the firm relative to the average firm in an industry, the greater the probable financial burden of installing air pollution control installations. In one industry, it has been reported, ${ }^{23}$ the cost of an air pollution control installation would exceed the value of the production facilities of many small firms in the industry.

\section{Conclusion}

We have attempted in this brief survey to evaluate the central problems economists have encountered in attempting to develop measures and tools to cope with the growing costs to society of air pollution. We have focused on the formidable difficulties posed by the pervasiveness of air pollution and described some of the efforts directed to its measurement and control. Here is a summary of our principal conclusions and suggestions for directions in which we might concentrate our efforts.

(I) Current estimates of total damage inflicted on this nation by air pollution are totally unreliable and most experts working on this problem are pessimistic in their prognosis for more acceptable estimates: this would not be an insurmountable difficulty for policy makers if there were a simple (linear) relation between the level of pollution and the costs of control. But, it is more likely that they are nonlinear. We suggest, therefore, that effective policy determination requires serious and substantially supported efforts to estimate the costs of air pollution and the benefits of abatement over a range of pollution levels.

(2) The very difficulty of this task, a difficulty stemming from the paucity of data and the primitive state of pollution measurement and control technology, suggests the need to experiment with alternative methods of studying control costs. ${ }^{24}$

(3) Air pollution cannot be studied and controlled in isolation; for it is one of a number of interrelated problems affecting the quality of the environment. As a consequence, significant economies would be possible if policies for the control of air pollution were to be treated as part of overall research and of planning for improvement of the quality of the environment and conservation of our scarce resources including clean air. Expenditures on roads, tunnels, air travel, conservation, mass

\footnotetext{
${ }^{28}$ Ietter from Albert W. Spitz to J. Spitz.

24 One possible approach would be patterned after a systems concept recently developed for a problem shed. This is a study in the Nashville, Tennessee area being conducted by Azriel Teller. According to Allen Kneese, "Teller was able to wed his cost figures . . . to an atmosphere diffusion model of the Nashville area." Kneese, supra note 5, at 534.
} 
transportation, urban development, recreational facilities, and industrial development must be guided by research and policies which take into account their interdependencies.

(4) There is no clear consensus on what kinds of economic measures should be taken to control pollution. The range of choices lies between, at one extreme, sole reliance on the market mechanism with schemes of effluent fees and the other extreme of complete reliance on government fiat with or without various forms of subsidies. We have asserted that the indeterminativeness of the market, the possibility of discrimination, and serious questions about its interpretation of business behavior raise serious qucstions about the former. Therefore, the solution may lie in between the two extremes, with some combination of regulatory setting of standards (such as those of the Air Quality Act of ${ }^{1967}$ ), and supplemental market incentives. But only further research and continuous experimentation can lead to optimal solutions; meanwhile, the mounting qualitative evidence of the cumulative consequences of air pollution suggest that we cannot wait for such "optimal" solutions. In the short run, "educated" guesses must serve us. 